\title{
Suplementação de Bovinos em Pastagem de Coastcross (Cynodon dactylon (L.) Pers) no Verão 1
}

\author{
Paulo Emílio Fernandes Prohmann², Antonio Ferriani Branco ${ }^{3}$, Clóves Cabreira Jobim³, \\ Ulysses Cecato ${ }^{3}$, Wagner Paris ${ }^{4}$, Gisele Fernanda Mouro ${ }^{2}$
}

\begin{abstract}
RESUMO - O experimento foi realizado no município de Luiziana, noroeste do Estado do Paraná, no período de outubro de 2000 a fevereiro de 2001. Foram utilizados 32 novilhos inteiros, com 13 meses de idade e peso inicial médio de $325 \mathrm{~kg}$, pertencentes a dois

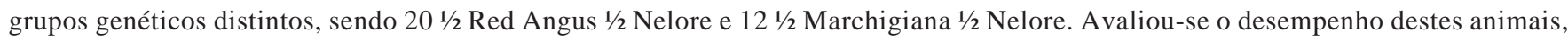
em quatro piquetes de Coastcross (Cynodon dactylon (L.) Pers), perfazendo um total de 5,05 ha e diferentes níveis de suplementação energética (na base de 0; 0,2; 0,4; e 0,6\% do peso vivo) com casca de soja. Foram realizadas estimativas da disponibilidade e da qualidade da forragem. Após 112 dias de experimento, observaram-se elevados ganhos de peso para todos os tratamentos (acima de 0,850 kg/dia).
\end{abstract}

Palavras-chave: casca de soja, desempenho, novilhos, pastejo

\section{Cattle Supplementation on Coastcross Pasture (Cynodon dactylon (L.) Pers) during the Summer}

\begin{abstract}
This trial was carried out in Luiziana, northwest of Paraná, from November 2000 to February 2001. Twenty-four animals with $325 \mathrm{~kg}$ of initial body weight and 13 months of age, from two different genetic groups, $1 / 2$ Red Angus $1 / 2$ Nellore (20) and $1 / 2$ Marchigiana $1 / 2$ Nellore (12) were used. Animal performance was evaluated, under grazing conditions on coastcross (Cynodon dactylon (L.) Pers) and four levels of soybean hulls: 0, 0.2, 0.4, and 0.6\% of body weight. Pasture production and quality were also evaluated. The experimental area consisted of four paddocks of Coastcross, with 5.05 ha of total area. After 112 days of experimental period, all treatments showed high gains per animal (above $0.850 \mathrm{~kg} /$ day).
\end{abstract}

Key Words: grazing, performance, soybean hulls, steers

\section{Introdução}

Na primavera, segundo Peruchena (1999), as forragens apresentam-se melhor balanceadas, com baixa concentração de matéria seca e fibra e máximos níveis de proteína e digestibilidade, sendo que, nessas condições, o consumo voluntário é alto. No verão, há aumento no conteúdo de matéria seca e na manutenção do conteúdo de proteína e pequeno aumento de parede celular, diminuindo a digestibilidade e o consumo voluntário varia de intermediário a alto.

O desempenho animal sob pastejo, expresso em produção por animal, é condicionado por diferentes fatores, como: genética animal e sua história prévia, consumo de forragem, valor nutritivo da forragem e eficiência na conversão da forragem consumida
(Gomide \& Gomide, 2001). Esses autores relatam a existência de diversos fatores que condicionam o consumo de forragem, podendo destacar-se o valor nutritivo (composição química e digestibilidade), a estrutura do relvado e oferta de forragem.

A percentagem e a densidade de lâmina foliar são os principais fatores que influenciam o consumo dos animais em pastejo (Alberto, 1997). O comportamento seletivo dos bovinos em pastejo orienta a escolha da dieta, baseando-se no componente lâmina foliar, em que se concentra o maior valor nutritivo da forragem (nitrogênio e carboidratos solúveis) (Peruchena, 1999).

A grama Coastcross apresenta inúmeras características desejáveis, como elevada produção de matéria seca (MS) por área, boa adaptação ao clima subtropical, boa relação folha/colmo e elevado valor

\footnotetext{
${ }^{1}$ Parte da dissertação do primeiro autor apresentada à Universidade Estadual de Maringá para obtenção do título de Mestre em Zootecnia.

${ }^{2}$ Estudante de Pós-Graduação em Zootecnia - UEM - Av. Colombo, 5790 - CEP: 87020-900. E-mail: pauloprohmann@yahoo.com.br; decozoo@yahoo.com; gfmouro@hotmail.com.

3 Professores do Departamento de Zootecnia - Bolsistas pesquisadores, CNPq - UEM - Av. Colombo, 5790 - CEP: $87020-900$. E-mail: afbranco@uem.br; ccjobim@uem.br; ucecato@uem.br.

4 Professor da Pontifícia Universidade Católica do Paraná. E.mail: wagner.paris@pucpr.br
} 
nutritivo (Bortolo et al., 2001). Os teores de proteína bruta da matéria seca de Coastcross são muito variáveis e dependente do manejo ao qual essa forrageira é submetida (Alvim et al., 1998).

A prática de suplementar bovinos em pastagens também tem sido pesquisada no período das águas, buscando otimizar o ganho animal, apesar de as forragens apresentarem maior produção e qualidade. Por esta razão, muitas indagações são feitas, questionando-se a viabilidade econômica desta técnica, tornando-se importante uma criteriosa avaliação.

Segundo Thiago (1999), a disponibilidade de nitrogênio para as bactérias ruminais normalmente não seria um fator limitante nas águas e a energia passaria a ser prioridade para suplementação. Dessa forma, o fornecimento de suplementos energéticos poderia melhorar a utilização das forragens, desde que cuidados fossem tomados em termos de manter um balanço energético/protéico no rúmen (PDR) e minimizar o efeito substituição.

A casca de soja é um resíduo agroindustrial proveniente do processamento do grão de soja, que pode ser utilizado na alimentação animal como alternativa na substituição de ingredientes nobres, resultando em menores custos. Por ser um resíduo produzido em grande quantidade, sua qualidade pode variar de acordo com os métodos do processamento, a origem ou variedade da soja e o grau de maturidade (Martin \& Hibberd, 1990). Segundo o NRC (1996), esse alimento contém, em média, $12,2 \%$ de PB, $80 \%$ de NDT e $66,3 \%$ de FDN.

Quando fornecidos a bovinos em pastagens, os suplementos contendo fibra altamente digestível (casca de soja, polpa cítrica etc) produzem menor efeito associativo negativo que os suplementos ricos em amido. Segundo Caton \& Dhuyvetter (1997), a redução do pH ruminal, associada ao aumento do amido na dieta, pode alterar a composição bacteriana do rúmen, aumentando a população de amilolíticas e diminuindo as decelulolíticas, com efeito negativo sobrea digestibilidade da parede celular e o consumo de forragem.

Diversos aspectos ligados à suplementação podem gerar resultados indesejáveis, podendo-se destacar o efeito de substituição. Este fenômeno pode ser definido como a redução no consumo de forragens, em função da suplementação fornecida. De acordo com Horn \& McCollum (1987), a ingestão de suplemento próximo de $0,7 \%$ do PV não produz efeito negativo sobre o consumo de forragem (substituição).

Este trabalho foi conduzido com o objetivo de avaliar o desempenho de novilhos mestiços inteiros, em pastagens de Coastcross (Cynodon dactylon (L.) Pers), submetidos a diferentes níveis de suplementação energética no verão, avaliando-se também a qualidade e produtividade da pastagem.

\section{Material e Métodos}

O experimento foi realizado na fazenda Dona Elisa, situada no município de Luiziana, noroeste do Estado do Paraná, no período de outubro de 2000 a fevereiro de 2001. O solo da região é classificado como Latossolo Vermelho Escuro (Rauen et al., 1996) e o clima, caracterizado como Subtropical Úmido Mesotérmico (Secretaria da Agricultura e do Abastecimento do Estado do Paraná, 2000).

A área experimental foi dividida com cerca elétrica de dois fios e constituída por quatro piquetes de Coastcross (Cynodon dactylon (L.) Pers), estabelecida há mais de três anos e com área total de 5,05 ha (1,2; 1,4; 1,1 e 1,35 ha/piquete). A água foi disponibilizada em bebedouros com bóia, os suplementos foram fornecidos em cochos de plástico (aproximadamente $0,5 \mathrm{~m} / \mathrm{animal}$ ) e o sal mineral em cochos de madeira (aproximadamente $13 \mathrm{~cm} /$ animal).

A área foi adubada com base nos resultados de análise do solo. A adubação com fósforo e potássio foi realizada em novembro de 2000, em cobertura, na forma de superfosfato simples e cloreto de potássio, respectivamente, em uma aplicação, na dosagem de $30 \mathrm{~kg} / \mathrm{ha} \mathrm{de}$ $\mathrm{P}_{2} \mathrm{O}_{5}$ e $70 \mathrm{~kg} / \mathrm{ha}$ de $\mathrm{K}_{2} \mathrm{O}$. A adubação nitrogenada (140 kg de N/ha) foi fracionada em duas aplicações, na forma de uréia, em novembro de 2000 e janeiro de 2001.

Foram utilizados 32 novilhos inteiros, devidamente identificados (brinco numerado), com 13 meses de idade e peso médio inicial de $325 \mathrm{~kg}$, sendo 20 1⁄2 Red Angus $1 / 2$ Nelore e 12 1/2 Marchigiana 1/2 Nelore.

Os novilhos permaneceram na pastagem de Coastcross e foram distribuídos em quatro tratamentos, com dietas complementadas com casca de soja, nos seguintes níveis: 0 (CS0); 0,2 (CS2); 0,4 (CS4); e 0,6\% (CS6) do peso vivo, com base na matéria seca. O sal mineral foi fornecido na quantidade de $50 \mathrm{~g} / \mathrm{cab} /$ dia a todos os animais.

Os animais foram pesados, sem jejum prévio, no início do experimento (27/10) e, a partir desta data, a cada 28 dias (quatro períodos), totalizando 112 dias experimentais. Foram everminados em janeiro e vacinados contra febre aftosa (novembro) e carbúnculo (janeiro).

R. Bras. Zootec., v.33, n.3, p.792-800, 2004 
Foi adotado o método de lotação contínua com carga variável, utilizando-se oito animais "testers" por piquete mais animais reguladores (Mott \& Lucas, 1952), sendo os quatro piquetes usados simultaneamente, sem qualquer período de descanso. Para reduzir a influência da variação de biomassa entre piquetes, os novilhos permaneceram em cada piquete por sete dias e, após esse período, eram transferidos para outro, em sentido pré-estabelecido de forma aleatória. Para a manutenção da biomassa residual desejada (próxima a $2000 \mathrm{~kg}$ de MS/ha), foram utilizados animais reguladores, mantendo a forragem em uma altura de 17 a $20 \mathrm{~cm}$.

A princípio, todas as avaliações das forragens se realizariam a cada 28 dias, porém em algumas ocasiões estas medições não puderam ser realizadas nas datas previstas em função das chuvas, muito freqüentes nesta época, prejudicando a atividade a campo. Com isso, as datas em que se realizaram as avaliações foram: 27/10, 11/12, 15/01 e 21/02.

As estimativas de biomassa residual de matéria seca (BR) foram realizadas nos quatro piquetes, conforme o método da dupla amostragem (Wilm et al., 1994). Para isso, foram coletadas aleatoriamente quatro amostras de $0,25 \mathrm{~m}^{2} \mathrm{em}$ cada piquete, cortadas rente ai solo, pesadas e secas em estufas com ventilação forçada a $65^{\circ} \mathrm{C}$, por 72 horas. Antes do corte, foi estimada visualmente a matéria seca da biomassa da amostra. Utilizando-se os valores das amostras cortadas e estimadas visualmente, foi calculada a biomassa de forragem (expressa em $\mathrm{kg} / \mathrm{ha}$ ) pela equação proposta por Gardner (1986).

A estimativa da taxa de acúmulo diário de MS (TAD) foi realizada pela equação proposta por Campbell(1966):

$$
\operatorname{TAD}_{j}=\frac{G_{i}-F_{i}{ }^{-}{ }_{1}}{n}
$$

em que: $\mathrm{TAD}_{\mathrm{j}}=$ taxa de acúmulo de matéria seca diária no período j, em $\mathrm{kg} \mathrm{MS/ha/dia;} \mathrm{G}_{\mathrm{i}}=$ matéria seca dentro das gaiolas no instante $i$, em $\mathrm{kg} \mathrm{MS} / \mathrm{ha}$; $\mathrm{F}_{\mathrm{i}-1}=$ matéria seca fora das gaiolas no instante $\mathrm{i}-1$, em kg MS/ha; $\mathrm{n}$ = número de dias do período $\mathrm{j}$.

Utilizou-se a técnica do triplo emparelhamento (Moraes et al., 1990) para estudar o acúmulo de biomassa no tempo, com três gaiolas de exclusão por piquete. O acúmulo de MS (A), nos diferentes períodos experimentais, foi calculado multiplicando-se o valor de TAD pelo número de dias do período.

A taxa de lotação (TL) foi calculada considerando a unidade animal (UA) como sendo $450 \mathrm{~kg}$ de PV, utilizando-se a seguinte fórmula:

$$
\mathrm{TL}=\frac{\text { UAt }}{\text { Área }}
$$

em que: $\mathrm{TL}=$ taxa de lotação, em UA/ha; UAt = unidade animal total; Área = área experimental total, em ha.

A oferta de forragem (OF) foi calculada de acordo com a seguinte fórmula:

$$
\mathrm{OF}=\frac{(\mathrm{BRD}+\mathrm{TAD})}{\mathrm{PV}} \times 100
$$

em que: OF = oferta de forragem, em kg MS/100 kg $\mathrm{PV} /$ dia; $\mathrm{BRD}$ = biomassa residual diária, em kg de MS/ha/dia; TAD = taxa de acúmulo diário, em kg MS/ ha/dia; PV = peso vivo dos animais, em $\mathrm{kg} / \mathrm{ha}$.

Após fracionar em sub-amostras (aproximadamente 50\% do material), a forragem coletada na dupla amostragem, fez-se a separação dos componentes estruturais: lâmina foliar (LF); bainha + colmo verde (BCV); e material morto (MM), dos quais obteve-se o peso seco individual e o porcentual de cada um. Os cálculos de LF/ha, BCV/ha e MM/ha foram obtidos do percentual de LF, BCV e MM, multiplicado pela biomassa residual na pastagem em cada data de coleta.

As análises para determinação do valor nutritivo do pasto foram realizadas em cada componente estrutural (LF, BCV e MM). Para isso, foram utilizadas as amostras coletadas na dupla amostragem em cada piquete. Analisou-se o teor de proteína bruta (PB), utilizando-se a metodologia descrita por Silva (1990), e a fibra em detergente neutro (FDN) e fibra em detergente ácido (FDA) segundo Van Soest et al. (1991). As análises de digestibilidade in vitro da matéria orgânica (DIVMO) foram realizadas pela metodologia descrita por Tilley \& Terry (1963), adaptada para o uso do rúmen artificial, desenvolvido por Ankom $^{\circledR}$, conforme descrito por Garman et al. (1997). Os valores da DIVMO foram utilizados para estimar o NDT da pastagem, conforme metodologia descrita por Kunkle \& Bates (1998):

NDT $=$ MO $\{[26,8+0,595($ DIVMO $)] / 100\}$ em que: NDT = nutrientes digestíveis totais (\%); DIVMO = digestibilidade in vitro da matéria orgânica (\%); MO = matéria orgânica (\%).

Os dados de ganho médio diário foram submetidos à análise de regressão, de acordo com o seguinte 
modelo estatístico:

$$
\mathrm{Y}_{i j}=\mu+\mathrm{b}_{1}\left(\mathrm{~N}_{i}-\mathrm{N}\right)+e_{i j}
$$

em que: $\mathrm{Y}_{i j}=$ valor observado das variáveis estudadas, relativo a cada indivíduo $j$, recebendo o nível $i$ de casca de soja; $\mu=$ constante geral; $b_{1}=$ coeficiente de regressão linear do nível de casca de soja sobre a variável $\mathrm{Y} ; \mathrm{N}_{i}=$ níveis de casca de soja nos suplementos, sendo $i=0 ; 0,2 ; 0,4$ e 0,6\% do PV; $\mathrm{N}=$ nível médio de casca de soja nos suplementos; $\mathrm{e}_{\mathrm{ij}}=$ erro aleatório inerente a cada observação.

\section{Resultados e Discussão}

A quantidade de biomassa residual (BR) encontra-se na Tabela 1. Observa-se que, na primeira avaliação (09/11), a área experimental apresentava-se com baixa BR, totalizando $1733 \mathrm{~kg} \mathrm{MS} / \mathrm{ha}$. Este valor está abaixo do preconizado por Corsi \& Martha Jr. (1998), pois, segundo esses autores, quando as plantas do gênero Cynodon são manejadas adequadamente, a biomassa é de aproximadamente $2500 \mathrm{~kg}$ MS/ha. Na segunda avaliação (11/12), com as condições climáticas favoráveis ao desenvolvimento da forrageira, a TAD observada foi elevada (74 kg MS/ha), com produção de $2380 \mathrm{~kg}$ MS/ha. Na terceira avaliação (15/01), a BR aproximou-se do nível mínimo recomendado e, na quarta avaliação (21/02), ocorreu redução de $436 \mathrm{~kg}$ MS/ha em relação à observada em 15/01. Em relação à avaliação de 11/12, nas duas últimas avaliações, o A declinou, diminuindo 466 e 771 kg MS/ha, totalizando produção diária de 55 e 31 kg MS/ha, respectivamente.

A OF média, durante os 112 dias de experimento, foi de 4,4 kg MS/100 kg PV. O menor valor da OF foi observado na primeira avaliação (2,6 kg MS/100 kg PV), sendo inferior aos demais períodos $(\mathrm{P}<0,05)$. A quantidade de forragem ofertada aos animais durante todo o experimento foi adequada, pois, além de permitir ganhos individuais elevados (Tabela 4), também proporcionou ganhos por área satisfatórios (Tabela 5).

Na Figura 1, pode-se observar a percentagem de LF, BCV e MM da forragem no verão, detalhando o comportamento individual de cada um desses componentes. A LF manteve-se próxima ou pouco acima de $20 \%$, enquanto a BCV atingiu proporções mais elevadas, em torno de 36 a 44\%. A MM permaneceu três períodos com alterações mínimas (35 a 36\%), com exceção da terceira avaliação, quando atingiu $42 \%$.

A biomassa (kg/ha) de lâmina foliar (LF), bainha + colmo verde (BCV), material morto $(\mathrm{MM})$ e a relação folha verde/colmo verde (LF/BCV) encontram-se na Tabela 2. Não houve diferenças $(\mathrm{P}>0,05)$ entre períodos para biomassa de LF e BCV, que apresentaram médias de 492 e 896 kg MS/ha nos 112 dias de experimento, respectivamente. Quanto ao MM, o maior valor (1087 kg/ha) foi observado no período 3 , sendo superior aos demais $(\mathrm{P}<0,05)$. A relação LF/BCV variou de 0,45 a 0,65 sem diferenças ( $\mathrm{P}>0,05)$ entre períodos. Segundo Bortolo et al. (2001), quanto maior a relação LF/BCV, melhor será o valor

Tabela 1 - Biomassa residual (BR), acúmulo (A), taxa de acúmulo diária (TAD), oferta de forragem (OF) e taxa de lotação (TL) em pastos de Coastcross, durante o verão

Table 1 - Residual biomass (RB), accumulation (A), daily accumulation rate (DAR), forage offer (FO), and stocking rate (SR) in Coastcross pastures during the summer

\begin{tabular}{|c|c|c|c|c|c|c|}
\hline & \multicolumn{4}{|c|}{$\begin{array}{l}\text { Datas } \\
\text { (Dates) }\end{array}$} & \multirow[t]{2}{*}{$\begin{array}{l}\text { Média } \\
\text { Mean }\end{array}$} & \multirow[t]{2}{*}{ CV (\%) } \\
\hline & 09/11 & $11 / 12$ & $15 / 01$ & $21 / 02$ & & \\
\hline BR (kg de MS/ha) & $1733^{\mathrm{a}}$ & $1808^{a}$ & $2476^{a}$ & $2040^{\mathrm{a}}$ & 2014 & 29,5 \\
\hline$R B(\mathrm{~kg}$ of $\mathrm{DM} / \mathrm{ha})$ & & & & & & \\
\hline A (kg de MS/ha) & - & $2380^{\mathrm{a}}$ & $1914^{\mathrm{a}}$ & $1143^{\mathrm{a}}$ & 1812 & 56,1 \\
\hline A ( $\mathrm{kg}$ of $D M / h a)$ & & & & & & \\
\hline $\begin{array}{l}\text { TAD (kg de MS/ha/dia) } \\
\text { DAR ( } \mathrm{kg} \text { of } D M / h a / d)\end{array}$ & - & $74^{\mathrm{a}}$ & $55^{\mathrm{a}}$ & $31^{\mathrm{a}}$ & 53,3 & 55,3 \\
\hline $\begin{array}{l}\text { OF (kg de MS/100 kg PV/dia) } \\
\text { FO (kg of DM/100 kg BW/d) }\end{array}$ & $2,6^{\mathrm{b}}$ & $5,2^{\mathrm{a}}$ & $5,1^{\mathrm{a}}$ & $4,7^{\mathrm{a}}$ & 4,4 & 18,1 \\
\hline $\begin{array}{l}\text { TL (UA/ha) } \\
\text { SR (AU/ha) }\end{array}$ & 5,4 & 5,9 & 6,3 & 4,9 & 5,6 & \\
\hline
\end{tabular}

CV: coeficiente de variação (CV: coefficient of variation).

Médias, na linha, seguidas de diferentes letras diferem $(P<0,05)$ pelo teste Tukey.

Means, within a row, followed by different letters differ $(P<0.05)$ by Tukey test.

R. Bras. Zootec., v.33, n.3, p.792-800, 2004 
nutritivo da planta forrageira.

Os teores de PB, FDN, FDA e NDT da pastagem de Coastcross são apresentados na Tabela 3. O percentual médio da PB da LF foi de 14,3\%, sendo o maior valor observado na segunda avaliação (15,7\%). Estes valores estão muito acima dos preconizados por Moore et al. (1991) para manutenção, que consideram $7 \%$ de $\mathrm{PB}$ como o mínimo para suprir as necessidades das bactérias ruminais. BCV e a MM, apresentaram teores médios de PB de 6,7 e 4,7\%, respectivamente. Em virtude do comportamento ingestivo dos bovinos, que, preferencialmente, selecionam as LF, torna-se importante o conhecimento qualitativo individual dos componentes da forragem.

Associando os dados da proporção dos componentes da planta (Figura 1) com a composição química de cada componente (Tabela 3), pode-se estimar a composição química da planta inteira. O teor médio de PB da planta inteira foi próximo de 7,6\%, valor muito abaixo do encontrado por Postiglioni \& Messias (1998), de $11,2 \%$. As diferentes condições existentes entre os experimentos mencionados são responsáveis pela desigualdade dos valores, pois Postiglioni \& Messias (1998) trabalharam em parcelas $\left(9 \mathrm{~m}^{2}\right)$ e realizaram cortes a cada 45 dias (quando a planta alcançava 45 à $50 \mathrm{~cm}$ ), sendo completamente diferente ao pastejo animal, estudado no presente trabalho.

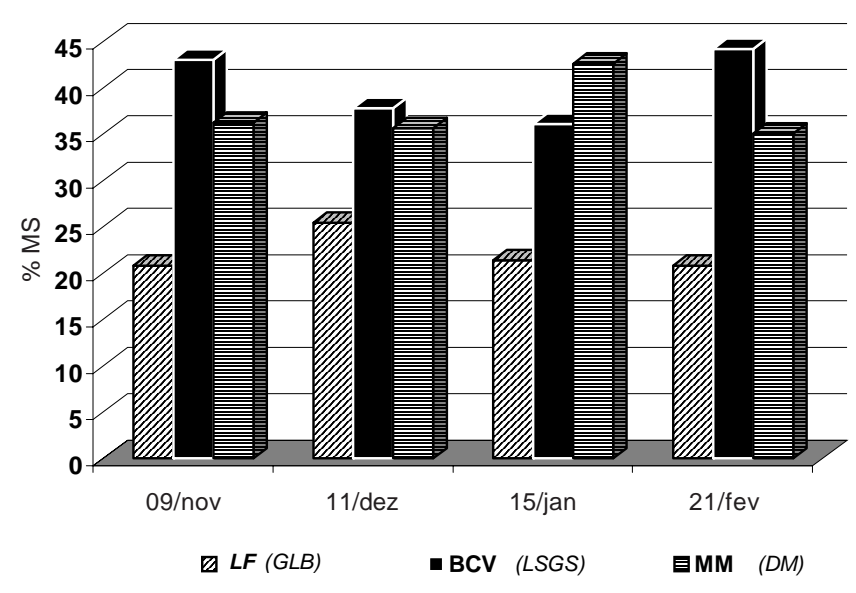

Figura 1 - Proporção dos componentes estruturais da Coastcross, no verão: lâmina foliar (LF) bainha + colmo verde (BCV); e material morto (MM).

Figure 1 - Proportion of structural components of Coastcross, in the summer: green leaf blade (GLB); leaf sheath + green stem (LSGS); and dead material (DM).
A LF, BCV e MM, apresentaram teores médios de NDT de 64,2; 57,2 e 42,7\%, respectivamente, enquanto a estimativa média para a planta inteira foi de 53,2\%. Gonçalves et al. (2000), trabalhando com intervalo de cortes de 63 dias, encontraram valor médio para a planta inteira na primavera e verão de 49,5\%.

A relação NDT:PB da LF manteve-se em todas as avaliações abaixo de 7 (média de 4,5), o que, segundo Moore \& Kunkle (1998), indica balanço adequado entre NDT e PB. Fazendo a mesma relação, desta vez com a planta inteira, o resultado médio das quatro avaliações indica valor limite de 7 , sendo que a primeira e a última avaliações apresentaram valores acima (7,9 e 7,4, respectivamente).

Os valores médios de FDN para a LF, BCV e MM foram de 65,1; 74,9 e 77,5\%, nesta ordem. A planta inteira apresentou teor médio de 73,3\%, semelhante ao observado por Rocha et al. (2001) e Menegatti et al. (1999) e superior ao citado por Assis et al. (1998), que encontraram valor de 71,9\%.

Os valores de FDA para LF, BCV e MM comportaram-se de maneira semelhante aos de FDN, onde cada um apresentou média de 30,5; 39,4 e 44,1\%. De acordo com Nussio et al. (1998), forragens com valores de FDA acima de 40\% são consumidas em baixos níveis. O FDA médio da planta inteira foi de 39,5 , sendo este valor muito próximo ao encontrado por Rocha et al. (2001), que observaram 40,3\%, e inferior ao citado por Bortolo et al. (2001), que encontraram valores entre 43,6 e 57,8\%.

No primeiro período, o ganho médio diário (GMD) foi de 1,427; 1,250; 1,321 e 1,404 kg (Tabela 4), para os animais suplementados com casca de soja nos seguintes níveis: 0 ; 0,$2 ; 0,4$; e $0,6 \%$ do peso vivo, respectivamente. Nesse período, observou-se uniformidade no ganho entre os tratamentos, sendo que o que apresentou o melhor desempenho (CS0) teve $12 \%$ a mais de ganho, em comparação ao tratamento com o menor desempenho (CS2). Esses elevados valores de GMD são conseqüência do ganho compensatório, pois esses animais haviam recebido suplemento durante toda a estação seca, alcançando ganhos acima de 0,938 kg/dia em outubro, sendo posteriormente submetidos a 20 dias de consumo de forragem de baixa qualidade, sem suplementação. A qualidade da LF foi satisfatória, pois apresentava teores de PB e de NDT de 12,8 e 64,7\%, sendo a relação NDT:PB de 5,0. Embora o GMD deste período tenha sido o maior e a forragem de boa

R. Bras. Zootec., v.33, n.3, p.792-800, 2004 
qualidade, a BR do pasto de Coastcross estava baixa, assim como a biomassa de LF e a relação LF/BCV.

No segundo período, todos os tratamentos proporcionaram menor GMD que no primeiro. CS0 apresentou a maior redução percentual (44\%), em relação ao período anterior. Nos outros três tratamentos, a diminuição no ganho foi menos intensa, variando de 20 a 36\%. Nesse período, apesar de não ter havido diferença para o terceiro e quarto, o A e a OF de forragem apresentaram os maiores valores de todo o experimento. A PB da LF, BCV, MM e, por consequência, da planta inteira $(8,45 \%)$ foram os mais elevados de todos os períodos. A LF alcançou o maior valor de NDT $(65,7 \%)$ e os menores de FDN e FDA (62,8 e 27,7\%). Os teores de FDN e FDA da planta inteira também foram os mais baixos, de 71,3 e $37,8 \%$, respectivamente. Como o plano nutricional mais baixo antecedente ao início do experimento, não foi muito longo (20 dias), constatou-se que o período referente ao ganho compensatório foi curto e praticamente restrito aos primeiros 28 dias. No segundo período, os ganhos foram compatíveis ao plano

Tabela 2 - Biomassa de lâmina foliar (LF), bainha + colmo verde (BCV) e material morto (MM), e a relação LF/BCV em pastagem de Coastcross, durante o verão

Table 2 - Green leaf blade (GLB), leaf sheath + green stem (LSGS), and dead material biomass (DM), and GLB/LSGS ratio of Coastcross during the summer

\begin{tabular}{lcccccc}
\hline & \multicolumn{5}{c}{$\begin{array}{c}\text { Data } \\
\text { Date }\end{array}$} & \multicolumn{3}{c}{$\begin{array}{c}\text { Média } \\
\text { Mean }\end{array}$} & CV (\%) \\
\cline { 2 - 5 } & $09 / 11$ & $11 / 12$ & $15 / 01$ & $21 / 02$ & & \\
\hline LF $^{*}$ & $412^{\mathrm{a}}$ & $533^{\mathrm{a}}$ & $622^{\mathrm{a}}$ & $401^{\mathrm{a}}$ & 492 & 57,8 \\
$\begin{array}{l}G L B \\
\mathrm{BCV}^{*}\end{array}$ & $853^{\mathrm{a}}$ & $820^{\mathrm{a}}$ & $1021^{\mathrm{a}}$ & $893^{\mathrm{a}}$ & 896 & 51,1 \\
$\begin{array}{l}L S G S \\
\mathrm{MM}^{*}\end{array}$ & $696^{\mathrm{b}}$ & $722^{\mathrm{b}}$ & $1087^{\mathrm{a}}$ & $719^{\mathrm{b}}$ & 806 & 37,9 \\
$\begin{array}{l}\text { DM } \\
\text { LF/BCV }\end{array}$ & $0,48^{\mathrm{a}}$ & $0,65^{\mathrm{a}}$ & $0,61^{\mathrm{a}}$ & $0,45^{\mathrm{a}}$ & 0,55 & 37,8 \\
GLB/LSGS & & & & & & \\
\hline
\end{tabular}

*LF, BCV, MM e LF/BCV em kg MS/ha (GLB, LSGS, DM and GLB/LSGS in kg DM/ha).

CV: coeficiente de variação (CV: coefficient of variation).

Médias, na linha, seguidas de diferentes letras diferem $(P<0,05)$ pelo teste Tukey.

Means, within a row, followed by different letters differ $(P<.05)$ by Tukey test.

Tabela 3 - Porcentagem de proteína bruta (PB), fibra em detergente neutro (FDN), fibra em detergente ácido (FDA) e nutrientes digestíveis totais (NDT*), nas frações da planta em pastagem de Coastcross, durante o verão (base matéria seca)

Table 3 - Percentage of crude protein (CP), neutral detergent fiber (NDF), acid detergent fiber (ADF), and total digestible nutrients (TDN) in the plant fractions of Coastcross pasture during the summer (dry matter basis)

\begin{tabular}{|c|c|c|c|c|c|c|c|c|c|c|c|c|}
\hline \multirow{3}{*}{$\begin{array}{l}\text { Data } \\
\text { Date }\end{array}$} & \multicolumn{4}{|c|}{$\begin{array}{c}\mathrm{LF} \\
G L B\end{array}$} & \multicolumn{4}{|c|}{$\begin{array}{l}\text { BCV } \\
\text { GSS }\end{array}$} & \multicolumn{4}{|c|}{$\begin{array}{c}\mathrm{MM} \\
D M\end{array}$} \\
\hline & PB & FDN & FDA & NDT & PB & FDN & FDA & NDT & PB & FDN & FDA & NDT \\
\hline & $C P$ & $N D F$ & $A D F$ & $T D N$ & $C P$ & $N D F$ & $A D F$ & $T D N$ & $C P$ & $N D F$ & $A D F$ & $T D N$ \\
\hline 09/11 & 12,8 & 64,4 & 31,6 & 64,7 & 6,0 & 73,6 & 39,6 & 59,9 & 4,8 & 77,4 & 45,4 & 43,9 \\
\hline 11/12 & 15,7 & 62,8 & 27,7 & 65,7 & 7,6 & 72,3 & 36,9 & 58,9 & 5,3 & 76,3 & 43,6 & 43,0 \\
\hline $15 / 01$ & 15,3 & 69,4 & 32,6 & 62,7 & 7,3 & 78,0 & 41,0 & 55,8 & 4,7 & 78,8 & 44,5 & 41,6 \\
\hline $21 / 02$ & 13,6 & 64,0 & 30,4 & 63,5 & 6,1 & 75,7 & 40,2 & 54,5 & 4,2 & 77,5 & 42,9 & 42,3 \\
\hline Média & 14,3 & 65,1 & 30,5 & 64,2 & 6,7 & 74,9 & 39,4 & 57,2 & 4,7 & 77,5 & 44,1 & 42,7 \\
\hline
\end{tabular}

*Estimado de acordo com a equação descrita por Kunkle \& Bates (1998).

*Estimated according Kunkle \& Bates (1998).

R. Bras. Zootec., v.33, n.3, p.792-800, 2004 
nutricional proporcionado pela qualidade e disponibilidade da pastagem mais o suplemento fornecido.

No período 3, verificou-se o menor GMD, com exceção de CS0, que teve o menor desempenho no último período. É interessante salientar que, no início deste período, a BR foi a maior de todo o experimento (2476 kg MS/ha) e o acúmulo, elevado (1914kg MS/ha). A biomassa de LF foi a maior de todo o experimento, assim como foram altas a de BCV, MM, a relação LF/BCV, a OF, os teores de PB da LF (15,3\%) e da planta inteira (8,0\%). Porém, foi estabelecida TL elevada (aproximadamente 6,3 UA/ha), o que proporcionou maior competição entre os animais na seleção da biomassa, evidenciada no período seguinte, onde a BR, LF, LF/BCV e a OF tiveram seus valores reduzidos.

No último período, foi possível observar uma diminuição no desenvolvimento da forragem, evidenciada pela queda no A (771 kg MS/ha) de 15/01 para 21/02 (Tabela 1). Houve uma queda no teor da PB da planta inteira (8,0 para 6,9\%), assim como da LF (de 15,3 para $13,6 \%$ ). Por ter sido imposta elevada TL anteriormente, reduziu-se o número de novilhos em pastejo, com a saída de animais reguladores, o que diminuiu a TL para 4,9 UA/ha. Com exceção de CS0, todos os tratamentos apresentaram retomadas nos ganhos, resultando no GMD de 0,837 kg neste período. Após análise de regressão dos dados obtidos para GMD durante os 112 dias experimentais, foi constatado que não houve resposta aos níveis de casca de soja utilizados $\left(\mathrm{R}^{2}=0,19\right)$.

Os dados médios dos quatro períodos demonstram que o fornecimento de casca de soja a $0,2 \%$ do PV (média de 0,828 kg/dia) elevou em 0,087 e 0,638 $\mathrm{kg}$ a quantidade de PB e NDT da dieta, enquanto 0,4\% do PV (média de 1,680 kg/dia) forneceu diariamente mais 0,176 kg de PB e 1,294 kg de NDT para os novilhos. A suplementação em nível de $0,6 \%$ (média de 2,535 kg/dia) forneceu 0,266 kg de PB e $1,952 \mathrm{~kg}$ de NDT adicionais.

Segundo Kunkle \& Bates (1998), quando existe disponibilidade de forragem, de baixa à média qualidade, cada kg de NDT suplementado produz aumento de $0,20 \mathrm{~kg} / \mathrm{dia}$ nos ganhos de peso. No presente trabalho, não foram constatados ganhos desta magnitude, encontrando-se aumentos de 0,07 e 0,06 kg/kg de NDT adicional, para CS4 e CS6, respectivamente, em virtude da boa qualidade do Coastcross.

O GMD obtido com os novilhos do grupo CS4 (0,949 kg/dia) é muito próximo ao observado por
Zervoudakis et al. (2001) que, trabalhando com novilhos mestiços castrados e suplementados (0,3\% do $\mathrm{PV})$, em pastos de Brachiaria decumbens com ração contendo $20 \%$ de $\mathrm{PB}$, alcançaram ganhos médios de $0,940 \mathrm{~kg} / \mathrm{dia}$.

Trabalhando com TL mais elevada (7,6 UA/ha) que a maior taxa verificada neste trabalho (6,5 UA/ha), Cruz et al. (2001) suplementaram bezerros mestiços em pastagens de Coastcross, com 3 kg de suplemento/animal/dia, contendo $18,8 \%$ de PB e $81,5 \%$ de

Tabela 4 - Ganho médio diário de novilhos suplementados com casca de soja em pastagem de Coastcross, durante o verão

Table 4 - Average daily gain of steers supplemented with soybean hulls in Coastcross pasture, during the summer

\begin{tabular}{lccccc}
\hline \multirow{2}{*}{$\begin{array}{l}\text { Tratamento } \\
\text { Treatment }\end{array}$} & \multicolumn{4}{c}{$\begin{array}{c}\text { Datas } \\
\text { Dates }\end{array}$} & $\begin{array}{c}\text { Média } \\
\text { Mean }\end{array}$ \\
\cline { 2 - 5 } & $24 / 11$ & $22 / 12$ & $19 / 01$ & $16 / 02$ & \\
\hline CS0 & 1,427 & 0,798 & 0,714 & 0,405 & $0,859^{\mathrm{a}}$ \\
CS2 & 1,250 & 0,833 & 0,470 & 0,857 & $0,853^{\mathrm{a}}$ \\
CS4 & 1,321 & 0,839 & 0,500 & 1,137 & $0,949^{\mathrm{a}}$ \\
CS6 & 1,404 & 1,119 & 0,333 & 1,095 & $0,988^{\mathrm{a}}$ \\
Média & 1,350 & 0,897 & 0,504 & 0,873 & 0,912 \\
Mean & & & & &
\end{tabular}

CSO: casca de soja a 0\% PV; CS2: casca de soja a 0,2\% PV; CS4: casca de soja a 0,4\% PV; CS6: casca de soja a 0,6\% PV.

CSO: $0 \%$ BW of soybean hulls; CS2: .2\% BW of soybean hulls; CS4: .4\% BW of soybean hulls; CS6: .6\% BW of soybean hulls.

$\mathrm{P}<0,08 ; \mathrm{GMD}=0,839+0,0243 \mathrm{X} ; \mathrm{R}^{2}=0,19$.

Período 1: de 27/10 a 23/11; Período 2: de 24/11 a 21/12; Período 3: de 22/12 a 18/01; Período 4: de 19/01 a 15/02.

Period 1: from 10/27 to 11/23; Period 2: from 11/24 to 12/21; Period 3 : from 12/22 to 01/18; Period 4: from 01/19 to 02/15.

Médias, na coluna, seguidas de diferentes letras diferem $(P<0,05)$ pelo teste Tukey.

Means, within a column, followed by different letters differ $(P<.05)$ by Tukey test.

Tabela 5 - Ganho de peso vivo por área (GPV/ha) e taxa de lotação (TL) no verão (112 dias)

Table 5 - Average body weight gain/ha (BWG/ha) and stocking rate (SR) in the summer (112 days)

\begin{tabular}{|c|c|c|c|c|c|}
\hline & \multicolumn{4}{|c|}{$\begin{array}{l}\text { Data } \\
\text { Date }\end{array}$} & \multirow[t]{2}{*}{$\begin{array}{l}\text { Total } \\
\text { Total }\end{array}$} \\
\hline & $24 / 11$ & $22 / 12$ & $19 / 01$ & $16 / 02$ & \\
\hline GPV/ha, kg & 269,8 & 185,4 & 124,8 & 148,3 & 728,3 \\
\hline $\begin{array}{l}\text { TL, UA/ha } \\
S R, A U / h a\end{array}$ & 5,1 & 5,9 & 6,3 & 4,9 & - \\
\hline
\end{tabular}

Período 1: de 27/10 a 23/11; Período 2: de 24/11 a 21/12; Período 3: de 22/12 a 18/01;Período 4: de 19/01 a 15/02.

Period 1: from 10/27 to 11/23; Period 2: from 11/24 to 12/21; Period 3: from 12/22 to 01/18; Period 4: from 01/19 to 02/15.

\section{R. Bras. Zootec., v.33, n.3, p.792-800, 2004}


NDT e observaram ganhos de 0,880 kg/dia. É importante salientar que os autores adotaram o sistema rotacionado com período de descanso de 20 dias. Cruz et al. (2001) relatam ganhos de $0,760 \mathrm{~kg} / \mathrm{dia}$ para bezerros alimentados apenas com Coastcross na estação das águas, sendo esse valor inferior ao observado no presente trabalho $(0,859 \mathrm{~kg} / \mathrm{dia})$, quando os animais receberam somente forragem.

Para o cálculo do ganho de peso vivo/ha (GPV/ha), foi necessária a agregação de todos os tratamentos para gerar apenas um valor, pois, como os lotes eram rotacionados a cada sete dias, foi impossível fazer inferências sobre diferenças entre tratamentos quanto à produção por hectare (Tabela 5).

As variações observadas no GPV/ha comportaram-se de maneira semelhante ao GMD, sendo os valores do primeiro período os mais elevados (269,8 kg/ha) e os do terceiro os menores (124,8 kg/ha). No segundo e quarto períodos, as médias do GMD foram muito próximas, o mesmo não ocorrendo com o GPV/ha $(185,4$ e 148,3) uma vez que a TL foi reduzida no quarto período, o que diminuiu a produção por área.

\section{Conclusões}

Pastagens de Coastcross adubadas e bem manejadas podem proporcionar elevados ganhos de peso individual (acima de 0,850 kg/dia) em novilhos precoces, durante o verão.

A suplementação com casca de soja, durante o verão, em níveis de até $0,6 \%$ do peso vivo, não produziu resposta em ganho de peso, em bovinos pastejando Coastcross.

\section{Literatura Citada}

ALBERTO, E. Efectos de la calidad de los forrajes y la suplementacion en el desempeño de rumiantes en pastoreo (con especial referencia a vacas lecheras). In: SIMPÓSIO SOBRE AVALIAÇÃO DE PASTAGENS COM ANIMAIS, 1997, Maringá. Anais... Maringá: Universidade Estadual de Maringá, 1997. p.149.

ALFIM, M.J.; XAVIER, D.F.; BOTREL, M.A. et al. Resposta do coast-cross (Cynodon dactylon (L.) Pers.) a diferentes doses de nitrogênio e intervalos de cortes. Revista Brasileira de Zootecnia, v.27, n.5, p.833-840, 1998.

ASSIS, M.A.; CECATO, U.; SANTOS, G.T. et al. Composição química e digestibilidade in vitro de gramíneas do gênero Cynodon submetidas ou não a adubação nitrogenada. In: REUNIÃO ANUAL DA SOCIEDADE BRASILEIRA DE ZOOTECNIA, 37., 2000, Botucatu. Anais... São Paulo: SBZ/Gnosis, [1998].CD-ROM. Forragicultura. FOR-198.

BORTOLO, M.; CECATO, U.; MARTINS, E.N. et al. Avaliação de uma pastagem de coastcross-1 (Cynodon dactylon (L.)
Pers) sob diferentes níveis de matéria seca residual. Revista Brasileira de Zootecnia, v.30, n.3, p.627-635, 2001.

CAMPBELL, A.G. Grazed pastures parameters: I. Pasture drymatter production and availability in a stocking rate and grazing management experiment with dairy cows. Journal of Agriculture Science, v.67, p.211-216, 1966.

CATON, J.S.; DHUYVETTER, D.V. Influence of energy supplementation on grazing ruminants: requirements and responses. Journal of Animal Science, v.75, p.533-542, 1997.

CORSI, M.; MARTHA JR., G. B. Manejo de pastagens para produção de carne e leite. In: SIMPÓSIO SOBRE MANEJO DA PASTAGEM, 15., 1998, Piracicaba. Palestras... Piracicaba: Fundação de Estudos Agrários Luiz de Queiroz, 1998. p.296.

CRUZ, G.M.; RODRIGUES, A.A.; TULLIO, R.R. et al. Avaliação do desempenho de bezerros nelore e cruzados desmamados recebendo dois níveis de suplementação concentrada em pastagem de Coastcross. In: REUNIÃO ANUAL DA SOCIEDADE BRASILEIRA DE ZOOTECNIA, 38, 2001, Piracicaba. Anais... Piracicaba: Sociedade Brasileira de Zootecnia, 2001. p.1182-1183.

GARDNER, A.L. Técnicas de pesquisa em pastagens e aplicabilidade de resultados em sistemas de produção. Brasília: IICA/EMBRAPA-CNPGL, 1986. 197p (Série publicações miscelâneas, 634).

GARMAN, C.L.; HOLDEN, L.A.; KANE, H.A. Comparison of in vitro dry matter digestibility of nine feedstuffs using three methods of analysis. Journal of Dairy Science, v.80 (supplement 1), p. 260, 1997.

GOMIDE, J.A.; GOMIDE, C.A.M. Utilização e manejo de pastagens. In: A PRODUÇÃO ANIMAL NA VISÃO DOS BRASILEIROS, 2001, Piracicaba. Palestras... Piracicaba: Fundação de Estudos Agrários Luiz de Queiroz, 2001. p.927.

GONÇALVES, G.D.; SANTOS, G.T.; JOBIM, C.C. et al. Digestibilidade in vitro de três cultivares do gênero Cynodon. In: REUNIÃO ANUAL DA SOCIEDADE BRASILEIRA DE ZOOTECNIA, 37., 2000, Viçosa. Anais... São Paulo: SBZ/Gnosis, [2000].CD-ROM. Forragicultura. FOR- 0423.

HORN, G.W.; McCOLLUM, F.T. Energy supplementation of grazing ruminants. In: GRAZING LIVESTOCK NUTRITION CONFERENCE, 1987, Jackson. Proceedings ... Jackson: University of Wyoming, 1987. p.125-136.

KUNKLE, W.E.; BATES, D.B. Evaluating feed purchasing options: energy, protein, and mineral supplements. In: FLORIDA BEEF CATTLE SHORT COURSE, 1998, Gainesville. Proceedings ... Gainesville: University of Florida, 1998. p.59-70.

MARTIN, S.K.; HIBBERD, C.A. Intake and digestibility of low-quality native grass hay by beef cows supplemented with graded levels of soybean hulls. Journal of Animal Science, v.68, p.4319-4325, 1990.

MENEGATTI, D.P.; ROCHA, G.P.; PAIVA, P.C.A. et al. Efeito de doses de nitrogênio sobre a produção de matéria seca e o valor nutritivo dos capins Coastcross, Tifton 68 e Tifton 85. In: REUNIÃO ANUAL DA SOCIEDADE BRASILEIRA DE ZOOTECNIA, 36., 1999, Porto Alegre. Anais... São Paulo: SBZ/Gnosis, [1999]. CD-ROM. Forragicultura. Adubação e fertilidade. FOR-165.

MOORE, J.E.; KUNKLE, W.E. Balancing protein and energy in forages. In: FLORIDA BEEF CATTLE SHORT COURSE, 1998, Gainesville. Proceedings... Gainesville: University of Florida, 1998. p.126.

MOORE, J.E.; KUNKLE, W.; BROWN, W.F. Forage quality and the need for protein and energy supplements. In:

R. Bras. Zootec., v.33, n.3, p.792-800, 2004 
FLORIDA BEEF CATTLE SHORT COURSE, 1991. Gainesville. Proceedings... Gainesville: University of Florida, 1991. p.196.

MORAES, A.; MOOJEN, E.L.; MARASCHIN, G.E. Comparação de métodos de estimativa de taxas de crescimento em uma pastagem submetida a diferentes pressões de pastejo. In: REUNIÃO ANUAL DA SOCIEDADE BRASILEIRA DE ZOOTECNIA, 27., 1990, Campinas. Anais... Campinas: SBZ, 1990. p.332.

MOTT, G.O.; LUCAS, H.L. The design, conduct and interpretation of grazing trials on cultivated and improved pastures. In: INTERNATIONAL GRASSLAND CONGRESS, 1952, Pennsylvania. Proceedings... Pennsylvania: State College Press, 1952. p.1385.

NATIONAL RESEARCH COUNCIL - NRC. Nutrient requirements of beef cattle. 7.ed. Washington, D.C.: National Academy Press, 1996. 242p.

NUSSIO, L.G.; MANZANO, R.P.; PEDREIRA, C.G.S. Valor alimentício em plantas do gênero Cynodon. In: SIMPÓSIO SOBRE MANEJO DA PASTAGEM, 15., 1998, Piracicaba. Palestras ... Piracicaba: Fundação de Estudos Agrários Luiz de Queiroz, 1998. p.296.

PEDREIRA, C.G.S.; MELLO, A.C.L.; OTANI, L. O processo de produção de forragem em pastagens. In: A PRODUÇÃO ANIMAL NA VISÃO DOS BRASILEIROS, 2001, Piracicaba. Palestras... Piracicaba: Fundação de Estudos Agrários Luiz de Queiroz, 2001. p.927.

PERUCHENA, C.O. Suplementacion de bovinos para carne sobre pasturas tropicales, aspectos nutricionales, productivos y economicos. In: REUNIÃO ANUAL DA SOCIEDADE BRASILEIRA DE ZOOTECNIA, 36., 1999, Porto Alegre. Palestras... São Paulo: SBZ/Gnosis, [1999] 17p. CD-ROM.

POSTIGLIONNI, S.R.; MESSIAS, D.C. Potencial forrageiro de quatro cultivares do gênero Cynodon na região dos campos gerais do Paraná. In: REUNIÃO ANUAL DA SOCIEDADE BRASILEIRA DE ZOOTECNIA, 36., 1998, Botucatu. Anais... São Paulo: SBZ/Gnosis, [1998]. CD-ROM. Forragicultura. FOR-017.

RAUEN, M.J.; SÁ, J.C.M.; OLIVEIRA, E.F. Forragicultura no Paraná. 1. ed. Londrina: Universidade Estadual de Londrina, 1996. 305p.
ROCHA, G.P.; EVANGELISTA, A.R.; LIMA, J.A. Digestibilidade, teores de FDN e FDA de três gramíneas do gênero Cynodon. In: REUNIÃO ANUAL DA SOCIEDADE BRASILEIRA DE ZOOTECNIA, 38., 2001, Piracicaba. Anais... Piracicaba: Sociedade Brasileira de Zootecnia, 2001. p.69-71.

SECRETARIA DA AGRICULTURA E DO ABASTECIMENTO DO ESTADO DO PARANÁ. “Paraná cidade: Luiziana”, 2000. http://www.paranacidade.org.br/base/ municipio.asp (04/02/2002)

SILVA, D.J. Análise de alimentos (métodos químicos e biológicos). 2.ed. Viçosa, MG: Universidade Federal de Viçosa, 1990. 165p.

THIAGO, L.R.L.S. “Suplementação de Bovinos em pastejo - aspectos práticos para seu uso na mantença e ganho de peso", 1999. http://www.cnpgc.embrapa.br/publicacoes/ naoseriadas/suplementhiago (14/10/2000).

TILLEY, J.M.A.; TERRY, R.A. A two stage technique for the "in vitro" digestion of forage crop. Journal of Britain Grassland Society, v.18, p.104-111, 1963.

Van SOEST, P.J.; ROBERTSON, J.B.; LEWIS, B.A. Methods for dietary fiber, and non-starch polysaccharides in relation to animal nutrition. Journal of Dairy Science, v.74, p.3583-3597, 1991.

WILM, H.G.; COSTELO, O.F.; KLIPPLE, G.E. Estimating forage yield by the double sampling method. Journal of American Society of Agronomy, v.36, p.194-203, 1994.

ZERVOUDAKIS, J.T.; PAULINO, M.F.; DETMANN, E. et al. Desempenho e características de carcaça de novilhos suplementados no período das águas. Revista Brasileira de Zootecnia, v.30, n.4, p.1381-1389, 2001. 